\title{
Students' Perception towards Code-Switching and Code-Mixing in Sociolinguistic: A Case at an English Education Major
}

\author{
Awab Abdulloh, Dr. Rizman Usman \\ Malang State University, Post-Graduate Language Education Program \\ awabandulloh@gmail.com
}

\begin{abstract}
This qualitative study will investigate English Education students' opinion towards code-switching and code-mixing; both in everyday and classroom use. In this study, it will employ an open-ended (short-answered questionnaire) with 13 questions that mainly focus students of English Education class of 2016-2018. The populations were chosen because the students of 2016-2018 have attended Sociolinguistic Course during semester 3. Moreover, to gather the population, the researcher spread the link of questionnaire written in Google Form by personally contacting several people via Whats App. Based on the findings obtained from the questionnaire, it can be inferred that the 20 respondents mainly spoke 3 languages (national: Indonesian, local: Javanese, foreign: English). Furthermore, it can be concluded that 11 respondents find code-switching and code-mixing of national, local and foreign languages acceptable to be used in everyday life and classroom situation. On the contrary, 3 respondents also see code-switching and code-mixing of national, local and foreign languages annoying and disturbing to be implemented in daily communication. Meanwhile, 6 respondents perceive code-switching and code-mixing of national, local and foreign languages as neutral to be executed in everyday and classroom situation.
\end{abstract}

Keywords: Sociolinguistic; Code-Switching; Code-Mixing; English Education Students

\section{Introduction}

The Oxford English Dictionary Supplement (1986) first noted the term sociolinguistic as contact linguistic (Gardner-Chloros, 2020). Contact linguistic emerged from the article "Man in India" by Hudson in 1939. In his article, it is found that the contact started from two people saying "hi." From here, Martinet (1953) named it contact linguistic because it resulted from a spontaneous interaction and contact with each other during the conversation (Scotton, 2017; GardnerChloros, 2020). As the time passes, Eugene Nida refers it as sociolinguistic in 1953 (Scotton, 2017; Gardner-Chloros, 2020).

Sociolinguistic definition can be generalized from two words, socio and linguistic. Socio relates to the society that interacts with each other; whereas linguistic refers to the language that the citizen speaks (Verhoven, 2017; Hymes, 
2020). In other words, the languages operate as social practice, and the linguistic resources available to speakers for style-shifting are influenced by the surroundings (Campoy \& Manuel, 2016; Campoy, 2020). According to Jaspers and Madsen (2016), sociolinguistic functions as a continuous process that is always being renewed as we interact worldwide. It is also acts to emphasize the communication process in order to create interactive meaning-making (Jaspers \& Madsen, 2016; Garcia \& Li, 2014). Based on Campoy and Manuel (2016), in the process of producing meaning, it progresses in terms of the linguistic differentiation which resulted from geographical (location of certain society groups), socio-demographic (ethnicities included in the area) and stylistic factors (the result from both factors). These factors will then construct an identity that is meaningful and is unique to each ethnic and racial group, specifically in bilingual and multilingual society (Campoy \& Manuel, 2016; Podesva 2012).

Paap, Schwitier and Paradis (2019) stated that bi or multilingual can be defined as two or more languages uttered by a person while communicating with interlocutors in a conversation. The bi or multilingualism of a person is namely received from their family and it then constructs diverse identities in a society (Paap, Schwitier \& Pardis, 2019). The identity will effect on a new habit of communication in the society, such as: code-switching and code-mixing, particularly in bilingual; and even multilingual society.

When two or more people communicate with each, we can call the system of communication as a code (Adhariyanty, 2015). Code is a term in sociolinguistics that expresses a language or a dialect (Thara \& Poornachandran, 2018).

Code-switching has been famously known since the year (1964) which focuses on the spoken situation, such as: German-Latin Code-Switching done by Luther's table talk in the research of Stolt (1964); or the speech of Russian aristocrats in the nineteenth century written by Tolstoy in his writing of Anna Karenina in (1975). The word code-switching has the meaning of the discourses produced in one or more sentences which might happen in the early statement or reply (Scotton, 2017). In other words, code-switching represents a unique verbal familiarity that permits switching between languages during a single conversation (Kuzyk, Friend, Severdija, Zesiger \& Poulin-Dubois, 2020). Scotton (2017) also 
stated that code-switching happen due to the interaction of several bi or multilingual people producing sentences. It will result to integrating both languages in the production and comprehension during the conversation (Beatty-Martinez \& Dussias, 2017). Linier to this, Bhatti, Shamsudin and Mat Said (2018) believed that the codes occur naturally during a conversation. This is due to the fact that codeswitching is beneficial if speakers wanted to say specific words, phrases or sentences in the language not currently in use, but they do not know the specific word to it which usually happens to bilinguals or multi-linguals that have the ability to simultaneously activate between both languages to deliver their message (BeattyMartinez \& Dussias, 2017; Kaushankaya \& Crespo, 2019; Yang, Hartanto \& Yang, 2016). Hence, code-switching will happen in this type of circumstances in order to minimize the risks of uttering the wrong words and to self-position themselves in performing their identity of a certain group (Frickle, Kroll \& Dussias, 2016; Garderner-Chloros, 2020).

Meanwhile, code-mixing started to be popular in the year of 1980, mainly the topic about the neural correlation of language switching (Johns, Kroff \& Dussias, 2018; Abutalebi \& Green, 2016). In the early years of its emergence, codemixing has provided a various testing ground for foundation to new cognitive and linguistic theories of multi-linguals and mono-linguals (Johns, Kroff \& Dussias, 2018). Code-mixing can be described as the mixture between two different codes in a sentence (Fanani \& Rudolf-Zico-Ma'u, 2018). In other words, it means the speaker makes two languages utterance that occurs in one sentence during a conversation (Helmie, Halimah \& Hasanah, 2020). It is usually done between two or more people that come from the same inside groups, mainly in terms of its ethnicity. Moreover, code-mixing has the purpose of expressing their feelings easily. This means that code-mixing will facilitate people to convey their thoughts without further thinking and miss communication between the interlocutors (Thara \& Poornachandran, 2018). Code-mixing can be in form of insertion and alternation. Insertion is putting words of different languages in the sentence (Fanani \& RudolfZico-Ma'u, 2018); whereas alternation is the switching of codes between conversational turns or utterance (Ikhsani, 2012). 
Both code-switching and code-mixing can be employed in everyday life, specifically in the educational field. In the context of English Language Teaching (ELT), code-switching can be utilized to provide active participation of students (Paramesvaran \& Wei Lim, 2018). Furthermore, it is to offer repetition as bi or multilingual students like to receive instructions given in both languages to foster their understandings of the explanation (Paramesvaran \& Wei Lim, 2018). As for the code-mixing, it is to keep students engage in the classroom. Moreover, it also can be used as a tool to make the instruction and message from the teacher more understandable (Syam, Sangkala \& Syarif, 2018).

However, when putting code-switching and code-mixing into practice, it might find some problems besides its benefits inside the classroom because not all instructors know the importance of both code-switching and code-mixing based on students' point of view. Thus, it is significantly important to know students' perception of code-switching and code-mixing to foster students' understanding and avoid miss-perceptions.

Several studies related to students' perception of code switching have been done since the past 4 years in countries like the study by Obaidullah (2016) in Bangladesh; Balam and Perez (2017) in Spain; Paramesvaran and Lim (2018) in Malaysia; Koylu (2018) in Turkey; Taula'bi'(2019) in Indonesia; and Al-Ahdal (2020) in Saudi Arabia.

Nonetheless, limited studies were conducted in the major that uses English as the Medium of Instruction (EMI), specifically in Indonesia and specific to knowing students' perception towards code-switching and code-mixing. For this reason, this study aims to fill the gap in order to know English Education Major Students' opinion towards both code-switching and code-mixing in every day situation and classroom atmosphere by using a short-answer questionnaire.

Based on the elaboration above, this study aims to know the answer for two questions:

1) What are the reasons students to code-switch and code-mix in their daily conversation and classroom situation?

2) How has code-switching and code-mixing impacted students' communication style and language proficiency? 


\section{Method}

This study was categorized as a descriptive qualitative; namely case study design. Cresswell (2016) stated that a case study design; includes individual or group cases or opinions. Furthermore, the data source of this study was obtained from the responses of students in at English Education Major, University of Jember, mainly classes of 2016 until 2018 in the short-answered online questionnaire written in Google Form. Students' response refers to the opinion that students give towards a certain question from the constructed questionnaire (Gillham, 2008). The reason for selecting the population is due to the fact that all classes of 2016 until 2018 have attended Sociolinguistic Course Class and they must have a basic knowledge of code-switching and code-mixing.

Meanwhile, it used a short-answered questionnaire as the instrument of the study that was done through Google Form and the link of the questionnaire was shared in Whats App. The total responses were 20 respondents who came from students of 2016 until 2018. According to Gillham (2008) a questionnaire is a way to gain someone's opinion by asking them several questions. The questionnaire is open-ended and consisted of 13 questions which have the purpose of: (a) knowing what languages students speak; (b) students' perception towards code-switching and code-mixing; (c) the reasons of switching and mixing the languages; (d) conditions that they execute code-switching and code-mixing; (e) relationship of code-switching and code-mixing; (f) students' experience when utilizing both codeswitching and code-mixing.

As for the data analysis method, this study employed the framework by Miles and Huberman (1994) as cited in Miles, Hubeman, Saldana (2014) which comprise of: (1) Data Collection; (2) Data Display; (3) Data Condensation; (4) Concluding the Data. First, the data were collected from students' responds in the shortanswered questionnaire written in Google Form. Next, the researcher sees the progress of whom and how many that have filled the questionnaire in the data display stage. After that, the researcher condensed the data by transcribing and coding the answers obtained from 20 respondents. Last, the researcher made a summary gained from 20 respondents for 13 questions. 


\section{Findings}

Based on the questionnaire, there are 13 questions that the respondents must answer shortly. The questionnaire basically has five main topics regarding to: (1) the languages students' speak (national, local and foreign); (2) students' perception and the reasons that students do code-switching and code-mixing; (3) the circumstances that students do code-switching; (4) the relationship between codeswitching and code-mixing; as well as (5) their own experience on code-switching and code-mixing which will be elaborated below

\section{Languages that Students Speak}

From the questionnaire, it can be seen that all students mainly speak 3 languages that consists of: national language, local language and foreign language. Their national language is Bahasa Indonesia, Javanese as their local language; as well as English as their foreign language.

\section{Students' Perception and Reasons of Using Code-Switching and Code-Mixing}

There were various perceptions of students related to code-switching and code-mixing. First, the majority of 11 respondents view code-switching and codemixing as a positive thing to be executed in everyday and classroom context. Next, 3 respondents consider it as annoying and disturbing (negative perception). Last, 6 other respondents regard it as a neutral phenomenon.

The reasons of using code-switching include vocabulary limitation, clarity, improving confidence in practicing, and talking a secret or gossiping. Based on the answer of the respondents, most participants consider that code-switching helps in improving clarity and or assist them if they have limited vocabularies. The respondents who have positive perception about code-switching said that code switching has enabled them to improve their confidence in practicing and learning English. Meanwhile, the respondents who have negative perception towards code switching addressed that the situation forced them to use code switching is due to the vocabulary limitation of their interlocutors, in order to ensure whether they get the intended message from their partners. 
As for the code-mixing, the respondents generally feel positive or okay, in particular for English language teaching (ELT) and learning process, or to improve clarity whilst communicating with their friends in informal situations or partners who have limited vocabulary or less capability in English. Besides that, it will also positively influence communication style with interlocutors as it improves clarity mainly for L2 learners. Nonetheless, some participants also address that code mixing is not appropriate to be used in more formal situations as it will reduce clarity and resulted to confusion when it is not used properly.

\section{Circumstances that Students Code-Switch and Code-Mix}

Students applied code-switching in several situations, such as: (a) explaining due to vocabulary limitation; (b) improving clarity while communicating with learners or partners or people who speak L1 with limited vocabulary to improve understanding; (c) talking with friend in an informal situation; (d) practicing or learning situation to improve their confidence and fluency; and (e) gossiping or talking a secret matter.

Meanwhile, students generally decide to use code mixing when they are trying to improve partners' understanding. Few of them also address that they do not have any specific reason for doing code switching as it has been a kind of their habit. A participant said that code switching may improve familiarity or be used to get closer to his speaking partners (e.g., beginners in learning English).

\section{Relationship of Code-Switching and Code-Mixing}

The majority of participants agreed that there is a relationship between code switching and code mixing with the effect of clarity on information and their understanding in classroom atmosphere. Only one participant says that there are no relationships and one participant is not sure about it.

\section{Experience while Implementing Code-Switching and Code-Mixing}

Based on respondents' experience, most respondents feel that their proficiency of English progressed when they applied code switching and code mixing in conversation and classroom context. Only two people says no, as based on their experience, their English has not much progressed by using code switching and code mixing. 


\section{Discussion}

\section{Languages that Students Speak}

According to Young (2016), language was formed by a variety of state interventions and institutional forces over hundreds of years. It can be in the form of human speech and writing; and as a result it produces an identity of a certain nation or ethnicity (Young, 2016).

Based on the theory of Kachru (1992) cited in Mc Kay (2018), Indonesia is categorized as an Expanding Circle Country, which means that English is considered as a foreign language. In other words, it is used and spoken after national and vernacular (local) languages, such as: Javanese, Madurese and Sundanese. This is because Indonesia is a multilingual country where people utilize the national language as a language of communication and solidarity (Bahasa Indonesia) for educational and formal purposes (Cahyani, De Courcy \& Barnett, 2016). National language is a language that is spoken by mass of people (Cohn \& Ravindranath, 2014). In Indonesia, the national language policy started when Indonesia proclaimed its nation in $17^{\text {th }}$ August 1945 (Cohn \& Ravindranath, 2014). As the policy of national language strengthens, it resulted to diffusion of multilingualism resulting in multiple abilities of languages, e.g.: Bahasa Indonesia with one or more vernaculars languages (Lo Bianco, 2012). The vernacular languages in Indonesia is the result of many ethnicities' culture; starting from Sabang until Merauke (BinTahir, 2020). In the Java Island, including Jember, the common vernacular (local) language is Javanese and it is spoken every day. Due to the various ethnicities and races, Indonesia views English as a foreign language. It means that English is spoken after national and vernacular language (Mc Kay, 2018). Besides that, English is used for particular purpose in the country, but it is hardly ever used for naturalistic communication outside the classroom (Cahyani, De Courcy \& Barnett, 2016).

\section{Students' Perception and Reasons of Using Code-Switching and Code-Mixing}

From the response of the questionnaire, it can be seen that the majority of students have a positive view (11 respondents); as well as neutral view (6 respondents) towards code-switching. It is stated that the code-switching enables students to enhance their communicative competence. This due to the fact that code- 
switching allows students to easily produces and selects a word that is most readily understandable to the interlocutors, namely in informal communication using a native language or foreign language (Kuzyk, Friend, Severdija, Zesiger \& PoulinDubois, 2020). In other words, if speakers wanted to say specific words, phrases or sentences in the language not currently in use, but they do not know the specific word, they can spontaneously switch between the languages (Beatty-Martinez \& Dussias, 2017; Kaushankaya \& Crespo, 2019). Besides that, corresponding to the questionnaire answer, it is also stated that code-switching helps students to achieve clarity. This is especially true because it provides valuable means of accomplishing the tasks of communicating in a clear and concise manner (Vigier \& Spencer-Oatey, 2017). In this case, code-switching can be a conscious process as they decide to apply to code-switching to explain the vocabularies to below-proficient students in classroom context (Gardner-Chloros, 2020). On the other side, as many as 3 people find that code-switching negative. This is due to the fact that they use codeswitching to foster the understanding of their friends. In order to do that, the specific person communicating with below-proficient student is usually required to select a particular code (words) whenever they explain the certain vocabularies (StylianouPanayi, 2015).

Meanwhile, for the code-mixing, most respondents feel that it is alright to use code-mixing in every day context. They stated that code-mixing benefits them as it will aid them to be more communicative, particularly when talking with friends in informal situations. This is because code-mixing have the advantage of transfer of linguistic units from one language into another and combine various words from two separate languages; which will result to a flexible communication and interaction process (Ansar, 2017; Lyne, 2016). Besides that, code-mixing will ease students to express their ideas and thoughts without any miscommunication or miss interpretation between the interlocutors (Thara \& Poornachandran, 2018). Nevertheless, the usage of code mixing can also reduce clarity as partners may get confused. This is because in code-mixing, students tend to combine phonological, lexical or grammar aspect from two or more languages (Hasan, 2015). 


\section{Circumstances that Students Code-Switch and Code-Mix}

It can be inferred from the findings that students perform code-switching in different situations, such as: (a) explaining due to vocabulary limitation; (b) improving clarity while communicating with learners or partners or people who speak L1 with limited vocabulary to improve understanding; (c) talking with friend in an informal situation; (d) practicing or learning situation to improve their confidence and fluency; and (e) gossiping or talking a secret matter.

In explaining the vocabulary, students code-switch because the switches of codes from their language to another helps the interlocutor understand (Ansar, 2017). According to Ansar (2017), this also relates to the previous point that the switch of languages helps in overcoming their problems in aspects like vocabularies. Moreover, it is identified that students also utilize code-switching while interacting with their peers. This is because code-switching is a form of linguistic purity that is applied in bilingual; and even multilingual community to accelerate students' confidence and fluency (Mabule, 2015). Last, code-switching also enables students to strengthen their identity by only including people who know both languages (Fanani \& Rudolf-Zico-Ma'u).

Meanwhile, students mostly decide to apply code mixing when they are trying to improve their partners' understanding because it will allow flexible communication for both parties (Lyne, 2016). Few of them also address that they do not have any specific reason for doing code switching as it has been a kind of their habit. This is because of their multiple language backgrounds; as a result, they rationalize and choose several languages that are suitable (Hasan, 2015).

\section{Relationship of Code-Switching and Code-Mixing}

Corresponding to the answer of the questionnaire, most of participants agreed that there is a relationship between code switching and code mixing with the effect of clarity on information and their understanding in classroom atmosphere. Mabule (2015) explained that the relationship of both code-switching and code-mixing lies in the implementation of two or more languages; either to change the words from native to foreign language and vice-versa; or to mix the words in order to create an accommodating conversation during the interaction process. Moreover, he also 
uttered that code-switching and code-mixing function as a tool to easily communicate with each other and avoid miscommunication (Mabule, 2015).

\section{Experience while Implementing Code-Switching and Code-Mixing}

Matching with the respondents' experience, nearly every respondent view code-switching and code-mixing increases their proficiency levels of English. This is especially true in the context of English Education Major that uses English as Medium Instruction (EMI) which can be defined as the teaching and learning process where it uses English as the main language of instruction (Macaro, Curle, Pun, An \& Dearden, 2017). Kim (2017) stated that students that are exposed EMI, tends to interact longer with English as their foreign language. Due to this, students feel that code-switching and code-mixing increases their English as they were able to learn new vocabularies (Bhatti, Shamsudin and Mat Said 2018).

\section{Conclusion}

To sum up, the respondents in general find that code-switching and code-mixing positive; whereas others find it neutral and negative. The positive respondents affirmed that code-switching and mixing allows for an easy-going conversation without any misinterpretation. Furthermore, both code-switching and mixing aid students to develop better English proficiency as they were able to acquire new vocabularies. Meanwhile, the negative respondents feel that code-switching and mixing decreases understanding level and may cause some confusion in grasping the interlocutor's utterances.

\section{References}

Abutalebi, J., \& Green, D. W. (2016). Neuroimaging of Language Control in Bilinguals: Neural Adaptation and Reserve. Bilingualism: Language and Cognition, 19(4), 689-698.

Adhariyanty, W. (2015). Code Switching for English Language Teaching and Learning in EFL Classroom. Jurnal Ilmiah Teknologi Dan Informasia ASIA (JITIKA), 9(2), 15-17. 
Al-Ahdal, A. A. M. H. (2020). Code Mixing in Arabic Conversations of College Students: A Sociolinguistic Study Of Attitudes To Switching To English. The Asian ESP Journal, 16 (1), 6, 19.

Ansar, F. A. (2017). Code Switching and Code Mixing in Teaching-Learning Process. English Education: Jurnal Tadris Bahasa Inggris, 10(1), 29-45. Balam, O., \& De Prada Pérez, A. (2017). Attitudes toward Spanish and CodeSwitching in Belize: Stigmatization and Innovation in the Spanish Classroom. Journal of Language, Identity \& Education, 16(1), 17-31. Beatty-Martínez, A. L., \& Dussias, P. E. (2017). Bilingual Experience Shapes Language Processing: Evidence from Codeswitching. Journal of Memory and Language, 95, 173-189.

Bhatti, A., Shamsudin, S., \& Said, S. B. M. (2018). Code-Switching: A Useful Foreign Language Teaching Tool in EFL Classrooms. English Language Teaching, 11(6), 93-101.

Bin-Tahir, S. Z. (2020). The Role of Local Language in Intercultural Communication among Societies of Buru Island.

Cahyani, H., De Courcy, M., \& Barnett, J. (2018). Teachers' Code-Switching In Bilingual Classrooms: Exploring Pedagogical and Sociocultural Functions. International Journal of Bilingual Education and Bilingualism, 21(4), 465479.

Cohn, A. C., \& Ravindranath, M. (2014). Local Languages in Indonesia: Language Maintenance Or Language Shift. Linguistik Indonesia, 32(2), 131-148.

Creswell, J. W., \& Poth, C. N. (2016). Qualitative Inquiry And Research Design: Choosing Among Five Approaches. Sage Publications.

Fanani, A., \& Ma'u, J. A. (2018). Code Switching and Code-Mixing in English Learning Process. Lingtera, 5(1), 68-77.

Fricke, M., Kroll, J. F., \& Dussias, P. E. (2016). Phonetic Variation in Bilingual Speech: A Lens for Studying the Production-Comprehension Journal of Memory and Language, 89, 110-137.

Gardner-Chloros, P. (2020). Contact and Code-Switching. The Handbook of Language Contact, 181-199. 
Gillham, B. (2008). Developing a Questionnaire. A\&C Black.

Hartanto, A., \& Yang, H. (2016). Disparate Bilingual Experiences Modulate Task-Switching Advantages: A Diffusion-Model Analysis Of The Effects Of Interactional Context On Switch Costs. Cognition, 150, 10-19.

Hasan, M. (2015). Reviewing The Challenges and Opportunities Presented by Code Switching and Mixing In Bangladesh. Journal of Education and Practice, 6(1), 103-109.

Helmie, J., Halimah, H., \& Hasanah, A. (2020). Code Mixing in College Students' Presentation: A Case in an Intercultural Communication Class. Indonesian Journal of EFL and Linguistics, 5(2), 403-417.

Hernández-Campoy, J. M. (2020). Sociolinguistic Styles. John Wiley \& Sons. Hymes, D. (2020). The Scope of Sociolinguistics. International Journal of The Sociology Of Language, 2020(263), 67-76.

Ikhsani, N. A. Code Mixing In the Articles of Gogirl! Magazine February. Lexicon, 1(3).

Jaspers, J., \& Madsen, L. M. (2016). Sociolinguistics in a Languagised World: Introduction. Applied Linguistics Review, 7(3), 235-258.

Kachru, B. B. (1992). World Englishes: Approaches, Issues and Resources. Language Teaching, 25(1), 1-14.

Kaushanskaya, M., \& Crespo, K. (2019). Does Exposure to Code-Switching Influence Language Performance in Bilingual Children?. Child Development, 90(3), 708-718.

Köylü, Z. (2018). The Use of L1 in the Tertiary L2 Classroom: Code-Switching Factors, Functions, and Attitudes In Turkey. Electronic Journal of Foreign Language Teaching, 15(2), 271-289.

Kim, E. G. (2017). English Medium Instruction in Korean Higher Education: Challenges and Future Directions. In English Medium Instruction In Higher Education In Asia-Pacific (Pp. 53-69). Springer, Cham.

Kuzyk, O., Friend, M., Severdija, V., Zesiger, P., \& Poulin-Dubois, D. (2020). Are There Cognitive Benefits of Code-Switching in Bilingual Children? A Longitudinal Study. Bilingual. Lang. Cognit, 23, 542-533. 
Kroll, J. F., Dussias, P. E., \& Bajo, M. T. (2018). Language Use across International Contexts: Shaping the Minds Of L2 Speakers. Annual Review of Applied Linguistics, 38, 60-79.

Lo Bianco, J. (2012). National Language Revival Movements: Reflections from India, Israel, Indonesia and Ireland.

Lyne, A. (2016). Code-Mixing In the Bilingual Preschool Child: Understanding the Communicative Purpose (Doctoral Dissertation, Mount Saint Vincent University).

Mabule, D. R. (2015). What is this? Is it Code Switching, Code Mixing or Language Alternating?. Journal of Educational and Social Research, 5(1), 339.

Macaro, E., Curle, S., Pun, J., An, J., \& Dearden, J. (2018). A Systematic Review of English Medium Instruction in Higher Education. Language Teaching, 51(1), 36-76.

Mckay, S. L. (2018). English As An International Language: What it is and what it Means for Pedagogy. RELC Journal, 49(1), 9-23.

Miles, M. B., Huberman, A. M., \& Saldana, J. (2014). Qualitative Data Analysis: A Methods Sourcebook.

Myers-Scotton, C. (2017). Code-Switching. The Handbook of Sociolinguistics, 217-237.

Obaidullah, M. (2016). Code Switching In EFL Classrooms: A Bangladeshi Perspective. Theory and Practice in Language Studies, 6(5), 924-934.

Paap, K., Schwieter, J. W., \& Paradis, M. (2019). The Bilingual Advantage Debate. The Handbook of the Neuroscience of Multilingualism, 701-735.

Paramesvaran, M. D., \& Lim, J. W. (2018). Code-Switching Practices in Malaysian Multilingual Primary Classroom from Teacher's And Students' Perspectives. Indonesian Journal of Applied Linguistics, 8(2), 254-264.

Podesva, R. J., Hall-Lew, L., Brenier, J., Starr, R., Lewis, S., Hernandez-Campoy, J. M., \& Cutillas-Espinosa, J. A. (2012). Condoleezza Rice and the Sociophonetic Construction of Identity. JM Hernández-Campoy Y JA Cutillas-Espinosa (Eds.), 65-80. 
Taula'bi, N. (2019). Students' Perception on the Language used by The Lecturers in Teaching English at the Eight Semester Students of English Department Of FKIP UKI Toraja. Teaching English as a Foreign Language Overseas Journal, 7(1), 32-45.

Thara, S., \& Poornachandran, P. (2018, September). Code-Mixing: A Brief Survey. In 2018 International Conference On Advances In Computing, Communications And Informatics (ICACCI) (Pp. 2382-2388). IEEE.

Stylianou-Panayi, N. (2015). Code Switching in an EFL Environment. Linguistics and Literature Studies, 3(6), 259-263.

Syam, U. K., Sangkala, I., \& Syarif, I. (2018). Code Mixing And Code Switching In The Classroom Interaction At SMA Negeri 2 Takalar. IOSR Journal of Humanities and Social Science (IOSR-JHSS), 23(7), 95-99.

Verhoeven, L. (2017). Sociolinguistics and Education. The Handbook of Sociolinguistics, 387-404.

Vigier, M., \& Spencer-Oatey, H. (2017). Code-Switching In Newly Formed Multinational Project Teams: Challenges, Strategies and Effects. International Journal Of Cross Cultural Management, 17(1), 23-37.

Young, R. J. (2016). That which is Casually Called a Language. PMLA, 131(5), 1207-1221. 